Nig. J. Biotech. Vol. 38 (2) : 101-108 (Dec 2021)

ISSN: 01891731

Available online at

http://www.ajol.info/index.php/njb/index

and www.biotechsocietynigeria.org

DOI: https://dx.doi.org/10.4314/njb.v38i2.11

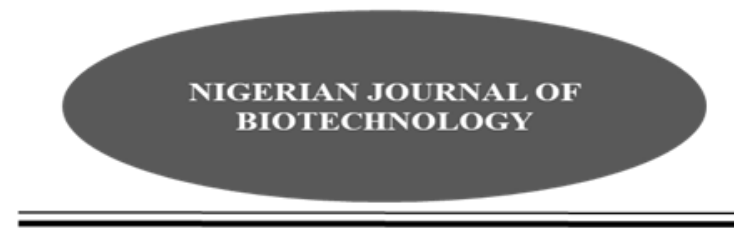

\title{
Cytological Study of 2n Pollen Formation in Musa
}

\author{
M. T. V. Adeleke ${ }^{1 *}$, M. Pillay ${ }^{2} \&$ B.E. Okoli \\ ${ }^{1}$ Department of Plant Science and Biotechnology, Rivers State University, Port Harcourt, Nigeria \\ ${ }^{2}$ Department of Biotechnology, Vaal University of Technology, Private Bag X021, Vanderbijlpark, South \\ Africa. \\ 3 Department of Plant Science and Biotechnology, University of Port Harcourt, Port Harcourt, Nigeria.
}

\begin{abstract}
Current Musa breeding strategies are complex and time consuming involving the selection of tetraploids from $3 x-2 x$ crosses. Secondary triploids are then obtained by crossing these tetraploids with diploids. Considering the very low hybrid seed set, routine embryo rescue procedures of hybrid seeds and the long growth cycle of banana, it takes approximately 10 12 years to produce an acceptable banana hybrid. The banana breeding process could benefit tremendously if triploid bananas could be obtained directly from $2 x-2 x$ crosses through the process of unilateral sexual polyploidization. There are few reports on the mechanisms through which Musa species produce $2 n$ pollen. This study investigated the type of meiotic irregularities that lead to $2 \mathrm{n}$ pollen formation in diploid, triploid and tetraploid Musa accessions using cytological analyses. The results showed that aberrations in cytokinesis and karyokinesis during microsporogenesis are possible mechanisms for $\mathbf{2 n}$ pollen formation in Musa. The meiotic aberrations described in this study have implications for Musa breeding. It appears that $2 \mathrm{n}$ pollen formation in Musa occurs via both first division restitution (FDR) and second division restitution (SDR).

FDR is said to be more promising in transferring more heterozygosity from parents to offspring.

Key words: Musa spp., abberrations, chromosomes, cytokinesis, karyokinesis.

*Corresponding author: mtadeleke@yahoo.co.uk
\end{abstract}

\section{Introduction}

Although meiosis is considered as a highly conservative process that leads to a reduction in the chromosome number in the gametes, mutations in the genes controlling the process lead to abnormalities, some of which can produce $2 \mathrm{n}$ gametes in plants (Pagliarini, 2000). The formation of $2 \mathrm{n}$ or diplogametes is a common feature in many plant species including wild potato (Camadro et al., 2008), Hibiscus (Van Laere et al., 2009), Begonia (Dewitte et al 2010), Turnera sidoides ( Kovalsky and Neffa 2016), Avena ventricosa (Nicoloudakis et al., 2018), lemon (Xie et al., 2020) and Cymbidium (Zeng et al., 2020). The production of $2 n$ gametes in plants is considered to be a dominant process in the origin of polyploid crop species (Harlan and de Wet, 1975) as well as the development of cultivars (Lim et al., 2001). More than $70 \%$ of flowering plants are polyploids (Leitch and Bennett, 1997). Musa is a polyploid complex that comprises diploid species and triploid and tetraploid accessions that originated from interand intraspecific hybrids between $M$. acuminata and M. balbisiana. The most common way of detecting $2 \mathrm{n}$ pollen is looking for large pollen size since this implies the presence of $2 n$ pollen in many genera (Van Laere et al., 2012). Some previous studies on Musa show that unreduced gametes do occur spontaneously in nature at low frequency (Dodds, 1943; Dodds and Simmonds, 1946; Sathiamoorthy and Balamohan, 1993). 
The normal pollen size for two wild banana species $M$. acuminata and $M$. balbisiana was reported to be $104 \pm 1 \mu$ and $94 \pm 2 \mu$, respectively (Ortiz, 1997). Our previous study showed that pollen sizes ranged from 84.30 to $107.20 \mu$ in 24 diploid and triploid banana accessions (Adeleke et al., 2004). Dodds (1943) indicated that pollen with a diameter of $129 \mu$ was considered haploid ( $n$ ) while the average diameter of $2 \mathrm{n}$ pollen was $147.6 \mu$. Ploidy analysis of hybrids derived from $2 x-2 x$ crosses in banana showed that some plants are triploids implying the formation of $2 \mathrm{n}$ gametes in Musa. Unreduced gametes are important in plant breeding as an efficient method to transfer germplasm from lower to higher ploidy levels (Vorsa and Bingham, 1979; Van Laere et al., 2012).

Diseases and pests such as black Sigatoka, Fusarium wilt, nematodes and weevils affect banana production throughout the world. Breeding is regarded as the most economical means of producing disease and pest resistant bananas. Current Musa breeding strategies are complex and time consuming involving the selection of tetraploids from $3 x-2 x$ crosses. Secondary triploids are produced from crossing tetraploids with diploids (Pillay et al., 2002). Considering the very low hybrid seed set, routine embryo rescue procedures of hybrid seeds and the long growth cycle of banana, it takes approximately $10-12$ years to produce an acceptable banana hybrid. The banana breeding process could benefit tremendously if triploid bananas could be obtained directly from $2 x-2 x$ crosses through the process of unilateral sexual polyploidization.

The formation of $2 \mathrm{n}$ gametes occurs via the phenomenon of nuclear meiotic restitution. Nuclear meiotic restitution is defined as the formation of a single nucleus with unreduced chromosome number in place of two nuclei with reduced chromosomes numbers, owing to the failure of either the first or second meiotic division (Ramanna, 1979). A number of meiotic abnormalities related to spindle formation, spindle function and cytokinesis are considered to be responsible for the formation of $2 \mathrm{n}$ gametes in several crop plants (Van Laere et al., 2012; De Storme and Geelen, 2020). They include parallel and tripolar spindles, premature cytokinesis I and II ( $p c$ I and $p c$ II) that lead to either first division or second division restitution (FDR and SDR, respectively) (Van Laere et al., 2012). There is now evidence for genetic control of the formation of unreduced gametes in plants (De Storme and Geelen, 2020). Investigations into the process of $2 \mathrm{n}$ gametes formation in Musa are limited. Second division restitution was postulated to be involved in megasporogenesis of plantains by Dodds and Simmonds (1946), Hutchinson (1966), Ortiz and Vuylsteke (1994) and Ortiz et al., (1995). Technical difficulties of staining Musa chromosomes have hindered studies concerning the mechanisms of $2 n$ gamete formation. However, new techniques using silver staining have made it possible to investigate $2 \mathrm{n}$ pollen formation in Musa (Adeleke et al., 2002).

The objective of this research was to investigate the type of meiotic irregularities leading to $2 \mathrm{n}$ pollen formation in diploid, triploid and tetraploid Musa accessions using cytological analyses.

\section{Materials and methods}

Plant Materials

For this study, 12 accessions of M. acuminata Colla. (representatives of the AA genome combination), 6 AAA, $3 A A B, 3 A B B$ triploid landraces, and 7 plantain-banana diploid hybrids, and 2 tetraploid cooking banana-banana hybrids. The female plantain parents of the hybrids were AAB landraces - 'Bobby Tannap' and 'Obino L'ewai' (French plantains), and ABB landraces - 'Bluggoe' and 'Fougamou'.

The male parent was mainly the wild diploid fertile seeded banana M. acuminata spp. burmannicoides Calcutta 4 (De Langhe \& Devreux, 1960); except M. balbisiana that was crossed with 'Fougamou'. Only four accessions 'Pisang lilin', 'High gate', the diploid hybrid 4600-12, and 'Pisang Jari Buaya' showed meiotic abnormalities during pollen formation. Normal meiosis was observed in the other accessions used in this study. Therefore only data for those plants that showed abnormalities are discussed. In this study giant pollen grains were regarded as $2 n$ pollen. Slide Preparation

Chromosome spreads from microsporocytes were prepared according to the procedure described in Adeleke et al. (2002). In summary, anthers were taken from young male buds and fixed in 3:1 ethanol-acetic acid solution with $1 \%$ ferric chloride as a mordant for $18-24$ hours at $4^{\circ} \mathrm{C}$. The contents of the anther lobes were squeezed out with the aid of a dissecting needle into a drop of LB01 buffer (15mM Tris, 2mM Na EDTA, 80mM $\mathrm{KCl}, 20 \mathrm{mM} \mathrm{NaCl}, 0.5 \mathrm{mM}$ spermine, $15 \mathrm{uM}$ mercaptoethanol, $0.1 \%$ Triton X-100, pH 7.5 
(Dolezel et al., 1989). The cells were pipetted into a microcentrifuge tube, rinsed several times in citrate buffer, pelleted and digested in an enzyme mixture (5\% cellulase, $1 \%$ pectinase and $1 \%$ pectolyase prepared in citrate buffer, $\mathrm{pH} 4.5$ ), and incubated at $37^{\circ} \mathrm{C}$ for $1-2$ hours. The pelleted cells were washed again in citrate buffer and resuspended in ice-cold $70 \%$ ethanol. A drop of the protoplast solution was placed on a clean slide and a drop or two of freshly prepared 3:1 ethanol - acetic acid placed over the cells shortly before the smear dried completely. The slide quality was assessed by observation in a phase contrast microscope. The best slides were air-dried and stained with silver nitrate according to the procedure described in Lacadena et al., (1984), except that incubation was done for 2-4 min. The slides were made permanent by treating in xylene for 30 min and then mounting in DPX.

\section{Photography}

Chromosomes were photographed in a Leitz Diaplan microscope using Ilford PAN F 50 film.

\section{Results and discussion}

One of the insights obtained from this study is that $2 \mathrm{n}$ pollen formation in Musa may be due to aberrations in cytokinesis and karyokinesis during microsporogenesis. The meiotic process in dividing pollen mother cells is usually very regular whereby the nuclear content of the cells first divide and move to opposite poles within the cell. This stage is followed by an equational division of the cytoplasm followed by the formation of a cell wall that separates the divided nuclear material. This procedure takes place in both the first and second meiotic divisions, except that the nuclear material that separates in meiosis I are homologous chromosomes, while those in meiosis II are sister chromatids. The whole process, therefore, should result in four daughter cells (pollen) with equal nuclear contents.

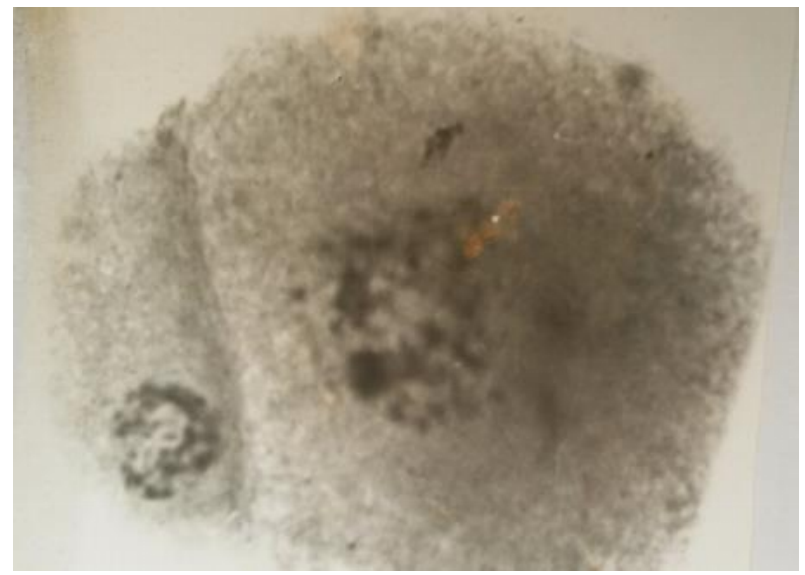

Fig. 1. Abnormal cytokinesis in telophase II of meiosis showing large and small cell.

$$
\text { Bar }=10 \mu \mathrm{m}
$$

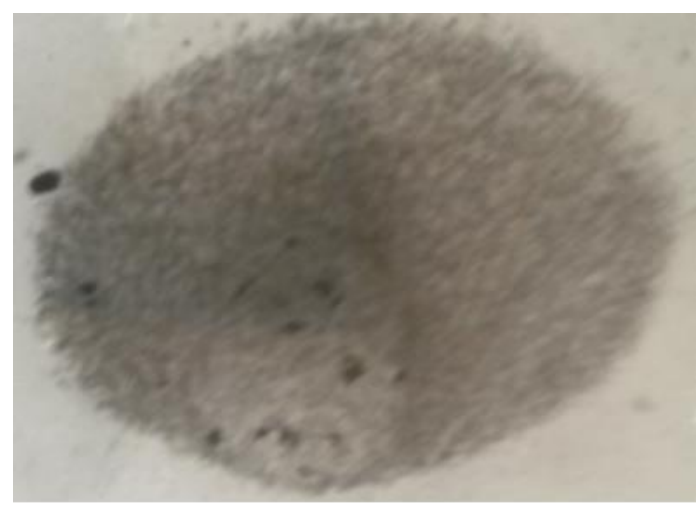

Fig 2. Aberration in meiosis showing one nucleated and one enucleate cell. 


$$
\text { Bar }=10 \mu \mathrm{m}
$$

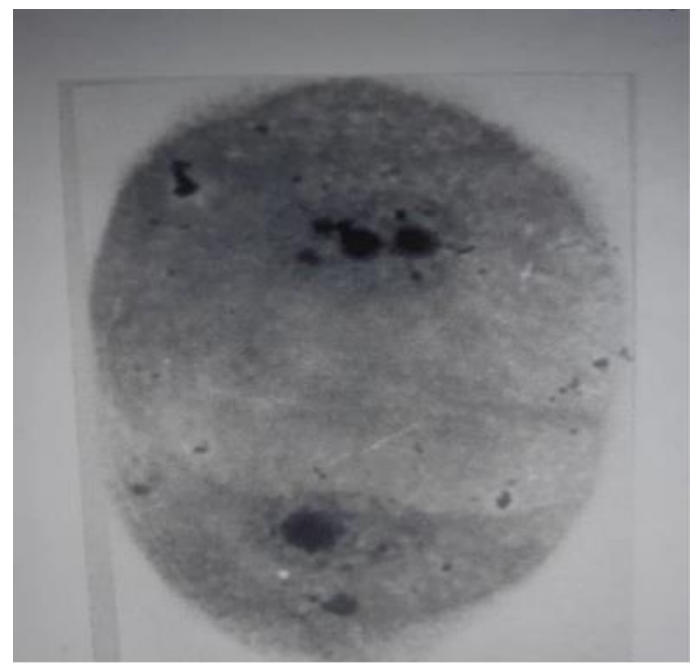

Fig 3. Photomicrograph showing asynchronous karyokinesis and cytokinesis. Bar $=10 \mu \mathrm{m}$

Three types of aberrations were identified in this study, during microsporogenesis in Musa. One type involved unequal cytoplasmic division after meiosis II. Figure 1 shows that the dyad comprises a very large cell and a small cell with corresponding large and small nuclei, respectively. This type of aberration was observed in 'Pisang lilin' (AA) a wild diploid banana and 'High Gate' (AAA), a dwarf mutant of 'Gros Michel', both of which have been classified as $2 n$ pollen producers (Ortiz, 1997). Judging from size alone, the larger cell most likely represents a $2 n$ gamete while the smaller cell appears to be a normal reduced gamete. The exact process that leads to the formation of the large and small cells was not clear in this study. Parallel spindle formation has been noted as one mechanism for $2 \mathrm{n}$ pollen grain formation (Mok and Peloquin, 1975). On the contrary, Carputo et al., (1995) reported, "parallel spindle is a necessary, but not sufficient condition for the formation of dyads". They also postulated that other mechanisms at the cytokinesis level could lead to the formation of dyads. Failure of cytokinesis has been reported to lead to $2 n$ gametes in Paspalum (Pagliarini et al., 2000), orchid (Storey, 1956) and Agave spp (GomezRodriguez et al., 2012), while Ramanna (1974) also reported that aberrant cytokinesis can lead to dyad formation. This may also be true for Musa although we were not able to observe any parallel spindles in this study.
Another type of aberration is illustrated in Fig 2 which shows all the nuclear material moved to only one of the two daughter cells leaving the other cell enucleate. There was equal division of the cytoplasm in meiosis I and one of the daughter cells appears to be undergoing a second nuclear division. There is no evidence of cytokinesis (Fig. 2). In this case, the single nucleus will contain the $2 n$ number of chromosomes. This abnormality was observed in the diploid hybrid 4600-12 that resulted from the cross between a plantain 'Bobby tannap' $x$ Calcutta 4 (diploid wild banana). It is likely that cytoplasmic incompatibility led to the elimination of chromosomes from one of the cells.

The third type of meiotic abnormality was observed in cells of the wild diploid 'Pisang jari buaya' and is illustrated in Fig 3. In this case the pollen mother cell had divided into two daughter cells that showed lack of synchrony in karyokinesis in one cell and absence of cytokinesis in the other. The nucleus in one of the two cells was divided into two but there was no evidence of cytokinesis. The cell had two nucleoli implying that the cell had a $2 n$ number of chromosomes. In general, an interphase or telophase nucleus has a single nucleolus. The second cell showed no indications of undergoing karyokinesis.

The meiotic aberrations described in this study have implications for Musa breeding. Banana breeding is difficult because of triploidy in 
cultivated accessions, low male and female fertility and differences in ploidy level that hampers the introgression of desirable characteristics from wild species into cultivated bananas (Pillay et al., 2002). Bastiaanssen et al. (1998) suggested that it is better to breed a ployploid crop species, such as the potato, at the diploid level in which the patterns of inheritance would be straightforward, the selection process more efficient and introgression of characters will be possible. Tezenas du Montcel et al. (1996) and Rowe and Rosales (1996) also advocated that the initial improvement of bananas should be carried out at the diploid level. Although diploid bananas present many interesting breeding characteristics, they are not easily accepted by consumers because they are generally smaller than triploids and are non- parthenocarpic. The formation of $2 n$ gametes in Musa opens up new opportunities for banana breeders to breed at the diploid level and then restore the triploid condition by making use of $2 n$ gametes via unilateral $(2 x-x)$ sexual polyploidization.

Whether the $2 \mathrm{n}$ gametes in Musa are formed via FDR (first division restitution, failure of $1^{\text {st }}$ division) or SDR (second division restitution, failure of $2^{\text {nd }}$ division) also present important opportunities for banana breeding. Genetic theory has shown that FDR transfers more efficiently heterozygosity from diploid parents to the tetraploid progeny, than SDR (Bingham, 1980). Theoretically, $2 n$ gametes that result from FDR transmit about $80 \%$ of parental heterozygosity to polyploid offspring, while SDR transmits just 40\% (Mendiburu and Peloquin, 1977). First division restitution gametes retain the parental genotypes to a large extent and are largely homogeneous while second division restitution gametes do not retain the parental genotypes and are largely heterogeneous (Ramanna, 1979). The meiotic aberrations in Musa illustrated in this study represent both FDR (Fig 2) and SDR (Fig 1 and Fig 3). The dyad cell that retains all the nuclear material (Fig. 2) would transmit more heterozygosity because homologous chromosomes remain together in the same daughter cell. If the two nucleoli in Fig. 3 remain in one cell, that cell would have the $2 n$ number of chromosomes. This would represent SDR because it contains 2 copies of sister chromatids of each chromosome and it will therefore not transmit much heterozygosity as in FDR.
There is a high degree of expected co-ordination between karyokinesis and cytokinesis in the normal course of meiosis. Meiosis involves specific cytological features and integrated events controlled by a large number of generally dominant genes which are stage-, site- and time specific (Taschetto and Pagliarini, 2003). However, this orderly process can be disrupted by meiotic mutations and is also affected by the environment (Veilleux, 1985). In this study, we reported aberrations observed in both cyto- and karyokinesis in Musa. Our results showed that aberrations in cytokinesis and karyokinesis during meiosis are possible mechanisms for $2 \mathrm{n}$ pollen formation in Musa.

These aberrations offer an explanation for the formation of $2 \mathrm{n}$ pollen production in Musa. However, one has to be aware that identifying mechanisms leading to unreduced gametes could be quite complex because different plants of the same species produce $2 \mathrm{n}$ gametes through different cytological mechanisms, which could be more than one within an individual plant (Parrot and Smith, 1984, Werner and Peloquin, 1991; Souza et al., 1999). In addition 2n gamete formation in Musa is affected by high solar radiation indicating that there may be seasonal variation in 2 n pollen production (Ortiz, 1997).

\section{Acknowledgements}

This research was supported partly with funding from the Directorate general for International Cooperation (DGIC), Belgium. Martina Adeleke was supported with funding from the International Institute of Tropical Agriculture, Ibadan, Nigeria.

\section{References}

Adeleke, M.T.V., Pillay, M. and Okoli, B.E. (2002). A novel method for examining meiotic chromosomes in Musa L. HortScience 37: 959961.

Adeleke, M. T. V., Pillay, M. and Okoli, B.E. (2004). Relationships between meiotic irregularities and fertility in diploid and triploid Musa L. Cytologia 69:387- 393.

Bastiaanssen, H.J.M., Ramanna, M.S., Huigen, D.J. and Jacobsen, E. (1998). Selection of diploid tuberous Solanum hybrids for $2 \mathrm{n}$-egg formation using 2x-4x-crosses. Euphytica 101:325-339.

Bingham, E.T. 1980. Maximizing heterozygosity in autotetraploids. In: Lewis WH. (ed) 
Polyploidy, Biological relevance. Plenum Press, New York, pp. 471-489.

Bretagnolle, F. and Thompson, J.D. (1995). Gametes with the somatic chromosomes number: mechanisms of their formation and role in the evolution of autopolyploid plants. New Phytol. 129:1-22

Camadro Elsa Lucila, Saffarano Sandra Karina, Espinillo Juan Carlos, Castro Mateo, Simon Phillip W. (2008). Cytological mechanisms of $2 n$ pollen formation in the wild potato Solanum okadae and pollen-pistil relations with the cultivated potato, Solanum tuberosum Genet. Resour. Crop Evol. 55(3):471-477.

Carputo, D., Cardi, T., Frusciante, L. and Peloquin, S. (1995). Male fertility and cytology of triploid hybrids between tetraploid Solanum commersonii ( $2 \mathrm{n}=4 \mathrm{x}=48,2 \mathrm{EBN})$ and PhurejaTuberosum haploid hybrids $(2 \mathrm{n}=2 \mathrm{x}=24$, 2EBN). Euphytica 83:123-129.

De Langhe, E. and Devreux, M. 1960. Une sousespece nouvelle de Musa

acuminata Colla. Bulletin du Jardin Botanique de I'Etat, Bruxelles 30: 375-380.

De Storme N., Geelen D. (2020). High temperatures alter cross-over distribution and induce male meiotic restitution in Arabidopsis thaliana. Commun. Biol. 3 1-15.

Dewitte, A., Eeckhaut, T., Van Huylenbroeck, J. et al. (2010). Meiotic aberrations during $2 n$ pollen formation in Begonia. Heredity 104: 215223.

Dodds, K.S. (1943). Genetical and cytological studies of Musa. V. Certain Edible Diploids. J of Genet. 45: 113-138.

Dodds, K.S. and Simmonds, N.W. (1946). Genetical and cytological studies of Musa. VIII. The formation of polyploid spores. J. of Genet. 47: 223-241.

Dolezel, J., Binarova, P. and Lucreti, S. (1989). Analysis of nuclear DNA content in plant cells by flow cytometry. Biol. Plant. 31: 113-120.
Gómez-Rodríguez, V.M., Rodríguez-Garay, B. and Barba-Gonzalez. R. 2012. Meiotic restitution mechanisms involved in the formation of $2 n$ pollen in Agave tequilana Weber and Agave angustifolia Haw. Springerplus 1:17

Harlan, J.R. and, de Wet, J.M. J. (1975). On Ö Winge and a prayer. The origin of polyploids.

Bot. Rev. 41: 361-390.

Hutchinson, D.J. (1966). Translocation configurations in a diploid banana. Can J Genet. Cytol. 8: 184-187.

Kovalsky, I.E. and Solís Neffa, V.G. (2016). Evidence of the production of $2 \mathrm{n}$ eggs in diploid plants of the autopolyploid complex Turnera sidoides L. (Passifloraceae). Plant Syst.

Evol. 302: 357-366.

Lacadena, J.R., Cermero, M.C., Orellana, J.J. and Santos, J.L. (1984). Evidence for wheat - rye nucleolar competition (amphiplasty) in triticale by silver - staining procedure. Theor. Appl. Genet. 67: 207-213.

Leitch, I.J. and Bennet, M.D. (1997). Polyploidy in Angiosperms. Trends Plant Sci. 2: 470-476.

Lim, K.B., Ramanna, M.S., Jong, J.H., Jacobsen, E. and van Tuyl, J.M. (2001). Indeterminate meiotic restitution (IMR): a novel type of meiotic nuclear restitution mechanism detected in interspecific lily hybrids by GISH. Theor. Appl. Genet. 103:219-230.

Mendiburu, A.O. and Peloquin, S.J. (1977). The significance of $2 \mathrm{n}$ gametes in potato breeding. Theor. Appl. Genet. 49: 53-61.

Mok, D.W.S. and Peloquin, S.J. (1975). Three mechanisms of $2 \mathrm{n}$ pollen formation in diploid potatoes. Can. J. Genet. Cytol. 17: 217-225.

Nikoloudakis, N., Aissat, A. and Katsiotis, A. (2018). Screening $A$. ventricosa populations for 2n gametes. Euphytica 214: 34.

Ortiz, R. (1997). Occurrence and inheritance of 2n pollen in Musa. Ann. Bot. 79: 449-453. 
Ortiz, R. and Vuylsteke, D.R. (1994). Genetics of apical dominance in Plantain (Musa spp., AAB group) and improvement of suckering behaviour. J. Am. Soc. Hortic. Sci. 119: 10501053.

Ortiz, R., Ferris, R.S.B. and Vuylsteke, D.R. (1995). Banana and plantain breeding. In: Gowen, S. (Ed.). Bananas and plantains. Chapman and Hall, U.K. pp. 110-146.

Parrot, W.A. and Smith, R. R. (1984). Production of $2 n$ pollen in red clover. Crop Sci. 24: 469-472

Pagliarini, M. S. (2000) Meiotic behavior of economically important plant species: the relationship between fertility and male sterility. Genet. Mol. Biol., 23, 4, 9971002.

Pagliarini, M.S., Takayama, S.Y., de Freitas, O.M., Carraro, L.R., Adamowski, E.V., Silva, N. and Batista, L.A.R. (1999). Failure of cytokinesis and $2 n$ gamete formation in Brazilian accessions of Paspalum. Euphytica 108: 129135.

Pillay, M., Tenkouano, A. and Hartman, J. (2002). Bananas and Plantains: Future challenges in Musa breeding. In: Crop Improvement, Challenges in the Twenty-First Century. Kang, M.S. (Ed.). pp. 223-252, Food Products Press, Inc., New York.

Ramanna, M.S. (1974). The origin of unreduced microspore due to aberrant cytokinesis in the meiocytes of potato and its genetic significance. Euphytica 23: 20-30.

Ramanna, M.S. (1979). A re-examination of the mechanisms of $2 n$ gamete formation in potato and its implication for breeding. Euphytica 28: 537-561

Ramanna, M.S., Kuipers, A.G.J. and Jacobsen, E. (2003). Occurrence of numerically unreduced

(2n) gametes in Alstroemeria interspecific hybrids and their significance for sexual polyploidization. Euphytica 133:95-106.

Rowe, P. and Rosales, F.E. (1996). Current approaches and future opportunities for improvement of major Musa (ABB) types present in Asian/Pacific Region: Saba, Pisang awak, Bluggoe. In: Frison EA et al. (eds). Proceedings of the workshop on New Frontiers in resistance breeding for nematode, Fusarium and Sigatoka, 2-5 October 1995, Kuala Lumpur, Malaysia. International Network for the Improvement of Banana and Plantain, Montpellier, France, pp.129-148.

Sathiamoorthy, S. and Balamohan, T.N. 1993. Improvement of banana. Adv. Hort. (India) 1: 303-335.

Souza, A.M., Pagliarini, M.S. and Carraro, I.M. (1999). Abnormal spindles in second meiosis in canola (Brassica napus and Brassica campestris). Braz. Arch. Biol. Technol. 42: 47-52.

Storey, W. B. (1956). Diploid and polyploid gamete formation in orchids. Proc. Am. Soc. Hortic. Sci. 68: 491-502.

Taschetto, O.M. and Pagliarini, M.S. (2003). Occurrence of $2 \mathrm{n}$ and jumbo pollen in the Brazilian ginseng (Pfaffia glomerata and $P$. tuberosa). Euphytica 133:139-145.

Tezenas, du Montcel, H., Carreel, F., Bakry, F. and Horry, J.P. (1996). Improve the diploids: the key for banana breeding. In: Frison EA et al. (eds). Proceedings of the workshop on New Frontiers in resistance breeding for nematode, Fusarium and Sigatoka, 2-5 October 1995, Kuala Lumpur, Malaysia. International Network for the Improvement of Banana and Plantain, Montpellier, France, pp 119-128

Van Laere K, Dewitte A, Van Huylenbroeck J. and Van Bockstaele E (2009) Evidence for the occurrence of unreduced gametes in interspecific hybrids of Hibiscus. J. Hortic. Sci. \& Biotech. 84(2):240-247

Van Laere, K., Dewitte, A. and Van Huylenbroeck, J. (2012). Detection and Induction of Unreduced Pollen in a Begonia Collection. In ICPHB2012: Program and abstracts

Veilleux, R. (1985). Diploid and polyploid gametes in crop plants: mechanisms of formation and utilization in plant breeding. 
Adeleke et al. / Nig. J. Biotech. Vol. 38 Num. 2 : 101-108 (December 2021)

Plant Breed. Rev. 3:253-288.

Vorsa, N. and Bingham, E.T. (1979). Cytology of $2 \mathrm{n}$ pollen formation in diploid alfalfa, Medicago sativa. Can. J. Genet. Cytol. 21:525530.

Werner, J.E. and Peloquin, S. (1991). Occurrence and mechanisms of $2 n$ egg formation in $2 x$ potato. Genome 34: 975-985.

Xie, K-D., Xia, Q-M., Peng, J., Wu, Z-M., Xie, ZZ., Chen, C-L., Guo, W-W., Zhang, Z.S. and Xie, L. (2020) Mechanism underlying $2 n$ male and female gamete formation in lemon via cytological and molecular marker analysis. Plant Biotechnol Rep 13,141-149 (2019). https://doi.org/10.1007/s11816-019-00525-4.

Zeng, R-Z., Zhu, J., Xu, S-Y., Du, G-H., Guo, H-R and Chen, J. (2020). Unreduced Male Gamete Formation in Cymbidium and Its Use for Developing Sexual Polyploid Cultivars. Frontiers in Plant Science 11. 